\title{
Bettina Rentsch
}

\section{Der gewöhnliche Aufenthalt im System des Europäischen Kollisionsrechts}

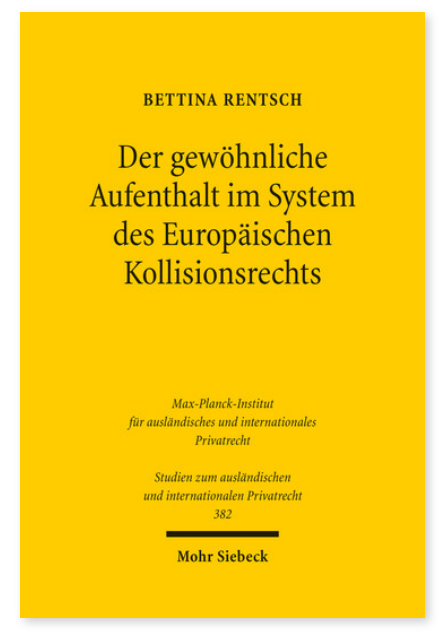

2017. XXXII, 465 Seiten. StudIPR 382

ISBN 978-3-16-155224-3

DOI 10.1628/978-3-16-155224-3

eBook PDF 89,00€

ISBN 978-3-16-155172-7

fadengeheftete Broschur $89,00 €$
Im Zuge der europäischen Kollisionsrechtsharmonisierung hat der gewöhnliche Aufenthalt erheblich an Bedeutung gewonnen. Inhaltlich und strukturell ist der Begriff aber weitgehend unerschlossen. Unklar ist auch, ob er einheitlich gehandhabt werden kann. Bettina Rentsch nimmt diese Unsicherheit zum Anlass, um den gewöhnlichen Aufenthalt sowohl historisch als auch konzeptionell und rechtspolitisch zu analysieren. Sie entwickelt eine rechtsaktübergreifende Begriffssystematik, die sich an Gegenstand und Reichweite der unionskollisionsrechtlichen Rechtswahlbestimmungen orientiert. Der so skizzierte, rechtswahlakzessorische Aufenthaltsbegriff nimmt das Gesetzesrecht ernst und führt unterschiedliche kollisionsrechtliche Rechtsquellen zusammen. So können Kohärenzdefizite im Europäischen Kollisionsrecht auf lange Sicht durch die Rechtsdogmatik eingehegt werden.

Die vorliegende Arbeit wurde mit dem Serick-Preis der Universität Heidelberg 2017 und dem Ruprecht-Karls-Preis 2018 ausgezeichnet.

Bettina Rentsch Geboren 1988; Studium der Rechtswissenschaften in Würzburg, Freiburg, Genf und Ann Arbor, USA (Master of Laws); 2016 Promotion; Juniorprofessorin für Bürgerliches Recht, Internationales Privatrecht und Rechtsvergleichung an der Freien Universität Berlin.

Jetzt bestellen:

https://mohrsiebeck.com/buch/der-gewoehnliche-aufenthalt-im-system-des-europaeischen-kollisionsrechts-9783161552243? no_cache=1

order@mohrsiebeck.com

Telefon: +49 (0)7071-923-17

Telefax: +49 (0)7071-51104 